\title{
Quality Improvement for A Shoe Laundry Using Integration Model of Service Blueprint, Failure Mode and Effect Analysis, and Fault Tree Analysis
}

\author{
Natalia Hartono ${ }^{1, *}$, Andry M Panjaitan ${ }^{1}$, and Abram Noel ${ }^{1}$ \\ ${ }^{1}$ Industrial Engineering, Faculty of Science and Technology, University of Pelita Harapan, Indonesia
}

\begin{abstract}
Nowadays, shoes are not just a casual footwear. Certain shoes can tell the social class of a person. The increase of shoe prices and social status of wearing expensive shoes became a trigger for the development of shoe laundry services. There were a service quality problems in a shoe laundry in Tangerang, Indonesia. Several methods to improve service quality was studied and it is decided to propose a new model, which is integration model of Service Blueprint, Failure Mode and Effect Analysis (FMEA) and Fault Tree Analysis (FTA). The research starts with identifying the problem with observation and interview, then build Service Blueprint. Based on the fail point that has been identified in Service Blueprint, the FMEA used to find which process is the most dominant cause of failure and the most urgent for improvement. The next step is using FTA to find the root cause of the failure of the dominant cause. After analyzing the FTA, the improvement was proposed and implemented. Service failure before and after implementation was compared to see the improvements. There are 6 suggestion and implemented. After the implementation, the error in each process was measured and it is found a decrease in error in each process.
\end{abstract}

\section{Introduction}

Nowadays, shoes are no longer just being footwear because certain shoes are able to show a person's social class and provide value for their own satisfaction because of the high price. For example, Nike Air Vapormax Flyknit iD [1] with the price of 3.8 million rupiah and Adidas Ultraboost X shoes is 3.4 million rupiah [2]. Not to mention the price of limited edition shoes that can be twice the price. These prices are close to regional minimum wage in a month in Jakarta, Indonesia. With the increasingly expensive price of shoes, shoe laundry began to grow like mushrooms in the rainy season in Indonesia. Shoe laundry provides shoe washing with a different method with cleaner and preserves the shoes compare than washing your own shoes.

\footnotetext{
*Corresponding author: natalia.hartono@uph.edu
} 
Shoe laundry which is become the object of this research is a Small-Medium Micro Company that only has 4 workers including the owner. This shoe laundry has the quality of service problems. One of the obvious problems is mistaken in the process of washing shoes. Based on initial observations and interview, these errors occur due to several factors, such as human factors and tool factors. Errors that occur are varied, such as input errors on queuing registration system, soap used does not match the shoe material and wrong washing technique due to an error in deciding the shoe material. These errors cause delay and raise complaints from the customer, which is a service quality problem of this shoe laundry.

Literature study shows that to improve the quality of service, there are many tools. Service blueprinting is a well-known model of planning the service process as a system and this model was originally introduced by Lynn Shostack [3]. The components in Service Blueprint are able to analyze each service process in detail. A service blueprint is a picture or map that portrays the customer experience and the service system, so that the different people involved in providing the service can understand it objectively, regardless of their roles or their individual points of view [4]. In the service blueprint, sub-processes and activities in a service process are depicted and the relationship between them is established and related to the customer's contact points so it is possible to analyze how a service process can best be designed to support good customer perceived service quality [3]. The blueprint can be analyzed to determine likely failure points or bottlenecks in the process, as well as customer pain points [4]. Service Blueprint needs to be combined with other methods to give more directed quality improvement analysis because there is no analysis of the cause of service failure in Service Blueprint.

There are two methods that widely and commonly used in manufacturing as a quality tool, namely Failure Mode and Effect Analysis (FMEA) and Fault Tree Analysis (FTA). Both of these methods can also be used in the service field. FMEA is a quality tool that allows the user to examine the process from the viewpoint of its potential for failure and plan for its control through service, product or process design requirements so the failure is designed out of the process before it reaches the customer [5]. FTA can be simply described as an analytical technique, whereby an undesired state of the system is specified, depicts the logical interrelationships of basic events that lead to the undesired event [6].

The application of FMEA in service and FTA in service has been done, for example, is research of Geum [7] and Carvalho [8]. Previous studies on service improvements using Service Blueprint, FMEA, and FTA were used separately or combination of two of the three tools. For example, Geum et al using FMEA to improve service productivity, Carvalho et al using FTA in service, Chuang's research that combines Service Blueprint with FMEA, and Bitner et al research using Service Blueprint $[7,8,9,10]$.

This research is the first that integrates Service Blueprint, FMEA, and FTA as an effort to improve the quality of service. Therefore, this research aims to improve quality service for a shoe laundry using an integrated model of Service Blueprint, Failure Mode, and Effect Analysis, and Fault Tree Analysis. The research was conducted from August - December 2017.

\section{Methodology}

The research starts with identifying the problem with observation and interview in a shoe laundry and after literature study, it is found that there are several tools to improve the quality of service. It is decided to integrate Service Blueprint, FMEA and FTA because of the strength of the tools. Service Blueprint will give a picture of the process and identify fail point and risk of excessive wait of the service. Based on the fail point that has been identified in Service Blueprint, the FMEA used to find which process is the most dominant 
cause of failure and the most urgent for improvement. The next step is using FTA to find the root cause of the failure of the dominant cause. The proposed integrated model of Service Blueprint, FMEA and FTA depict in Fig 1. After analyzing the FTA, the improvement was proposed and implemented. Service failure before and after implementation was compared to see the improvements.

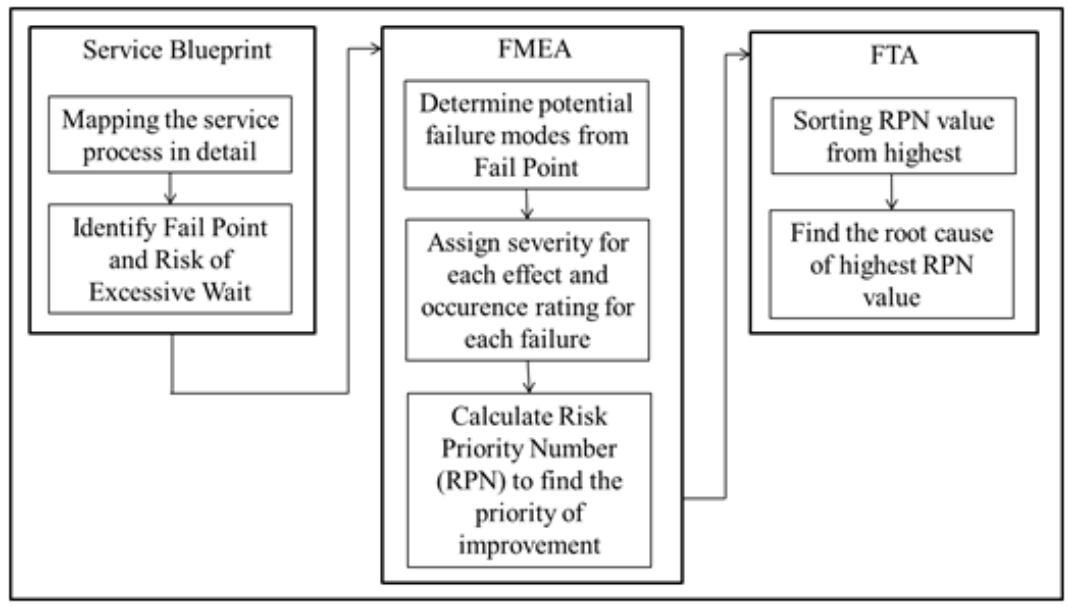

Fig 1. Proposed Integrated model of Service Blueprint, FMEA, and FTA

\section{Data Collection and Analysis}

A brief description of the shoe laundry that used in this research is that its start in 2016 with only 4 employees, and its location in Lippo Village, Karawaci, Tangerang, Indonesia. The shoe laundry offers a full cleaning service, unyellowing (whitening), recoloring, and repaint.

The first step is taken data to depict all of the processes and identify the fail points and risk of excessive wait where each process is described in the five Service Blueprint components: customer action, physical evidence, the front of stage interaction, back of stage interaction and support processes. Service Blueprint very useful to see how customer involves in the service and identify the fail point and risk of an excessive wait. The results show there are 11 fail points. There is no time data on service processes, so there is no standard time for every process. There are five processes that need to have time standard, so this research collect the data and calculate the standard time. The steps to calculating standard time took the time of the process, validate the data with a normality test, uniform test, and adequacy test, then determine the normal time and standard time. The standard time becomes standard for the shoe laundry to determine their service target time. The fail point used as input in FMEA to find the most urgent process that needs to improve first. Severity and detection value determined based on theory and discussion with the shoe laundry owner while occurrence value from observation. The FMEA table depicted in Table 1

In order to choose which failure mode that will get analyze further, the RPN value is sorted descending from largest to smallest value. The first quartile represents $25 \%$ of the highest RPN value in FMEA. The first quartile shows there are 4 processes with highest RPN, but because the $5^{\text {th }}$ in the list has the same RPN value with the $4^{\text {th }}$, then there are 5 processes that analyze further using Fault Tree Analysis (FTA). 
Table 1. Failure Mode Effect Analysis

\begin{tabular}{|c|c|c|c|c|c|c|}
\hline Process & Failure Mode & Failure Effect & Severity & Occurence & Detection & $\begin{array}{c}\text { Risk } \\
\text { Priority } \\
\text { Number }\end{array}$ \\
\hline $\begin{array}{l}\text { Input data (customer } \\
\text { data, shoes data, shoes } \\
\text { service) }\end{array}$ & $\begin{array}{l}\text { Wrong input data in the } \\
\text { system }\end{array}$ & Wrong printed receipt & 7 & 8 & 3 & 168 \\
\hline $\begin{array}{l}\text { Give receipt that also as } \\
\text { slip to took the shoes }\end{array}$ & Give the wrong receipt & $\begin{array}{l}\begin{array}{l}\text { Causing confusion to } \\
\text { customer and employee }\end{array} \\
\end{array}$ & 9 & 1 & 3 & 27 \\
\hline \multirow{2}{*}{$\begin{array}{l}\text { Brushing the shoes (upper } \\
\text { with soap "A" and sole } \\
\text { with soap "B") }\end{array}$} & Damaged shoes & $\begin{array}{l}\text { Customer } \\
\text { dissappointed/angry }\end{array}$ & 7 & 1 & 2 & 14 \\
\hline & Shoes still dirty & Rework & 4 & 10 & 2 & 80 \\
\hline $\begin{array}{l}\text { Removing spot from } \\
\text { rubber surface (usually } \\
\text { the sole) }\end{array}$ & There is still spot & Rework & 5 & 1 & 3 & 15 \\
\hline $\begin{array}{l}\text { Brushing inner sole and } \\
\text { shoelace with soap "C" }\end{array}$ & \begin{tabular}{|l} 
Insole or shoelace \\
broken
\end{tabular} & \begin{tabular}{|l|} 
Customer \\
dissappointed/angry
\end{tabular} & 7 & 1 & 2 & 14 \\
\hline \multirow{2}{*}{ Quality control } & $\begin{array}{l}\text { Insole or shoelace still } \\
\text { dirty }\end{array}$ & Rework & 4 & 9 & 3 & 108 \\
\hline & $\begin{array}{l}\text { Dirty shoes pass the } \\
\text { inspection }\end{array}$ & There is still spot & 2 & 9 & 4 & 72 \\
\hline $\begin{array}{l}\text { Call the customer (mostly } \\
\text { Whatsapp) }\end{array}$ & \begin{tabular}{|l|}
$\begin{array}{l}\text { Call the wrong } \\
\text { customer }\end{array}$ \\
\end{tabular} & $\begin{array}{l}\text { Causing confusion to } \\
\text { customer and employee }\end{array}$ & 1 & 1 & 4 & 4 \\
\hline Give the finished shoes & $\begin{array}{l}\text { Give the wrong finished } \\
\text { shoes }\end{array}$ & $\begin{array}{l}\text { Causing confusion to } \\
\text { customer and employee }\end{array}$ & 5 & 1 & 2 & 10 \\
\hline Write the address & Input the wrong address & $\begin{array}{l}\text { The courier got lost so } \\
\text { the delivery time is longer } \\
\text { than it should be }\end{array}$ & 5 & 8 & 2 & 80 \\
\hline $\begin{array}{l}\text { Packing the finished } \\
\text { shoes }\end{array}$ & \begin{tabular}{|l|}
$\begin{array}{l}\text { Misplacement the shoes } \\
\text { when packing }\end{array}$ \\
\end{tabular} & Shoes damaged or dirty & 5 & 1 & 2 & 10 \\
\hline \multirow[b]{2}{*}{ Send the shoes } & The courier got lost & Delay in delivery & 5 & 10 & 5 & 250 \\
\hline & $\begin{array}{l}\text { Time delivery not } \\
\text { appropriate with } \\
\text { agreement }\end{array}$ & $\begin{array}{l}\text { Customer is not at } \\
\text { home/place }\end{array}$ & 5 & 1 & 4 & 20 \\
\hline
\end{tabular}

FTA used to find the root cause of failure to generate a logical solution to solve the problems. Each FTA made based on the results of discussions with the owner of the shoe laundry and the employee.

1. FTA for The courier got lost

There is 4 basic events (root cause) of the courier got lost. The first is the lack of knowledge of employees of the intended address. The second root is a human error caused by having health problems or personal problems that interfere with his thinking while working. Through the results of interviews with all employees, personal problems that have occurred is a family problem that ends up becoming a financial problem. Next root is because the previous process inputs the wrong address. The fourth root is a guided error in the GPS application. Every courier who delivered always using GPS applications so that this GPS application becomes crucial. There are 3 causes of error in the GPS application, the first one is because the GPS does not lead to the appropriate path, this can be due to any repair or closure or change of the road because the GPS is not updated. Guidance errors in the GPS application can also be caused by a human error due to incorrect enter the address or wrong destination address.

2. FTA for Wrong input data in the system

The next type of error is an error entering data into the system. This can lead to a lot of errors in subsequent processes, one of which is the shoe washing process that will be discussed on the next FTA. There are several causes of the process error, that is because it is caused by the employee mishears or the customer is giving the wrong info 
or not complete info, otherwise, it could be employees not focus when entering data to the system due to physical health problems or personal problems. Another cause is the lack of employee knowledge of the types of shoes. This can be due to lack of training from the owner or also because of the lack of guidance for the employee.

3. FTA for Insole or shoelaces still dirty

The root cause is the same with shoes still dirty, the difference is that the shoelaces and insole have the same washing treatment, so there is no cause of wrong input data.

4. FTA for shoes still dirty

This is caused by two major factors namely internal and external. The external factor is from the customer itself, where the shoes already damaged or too dirty and have a permanent stain. This can cause all efforts to clean these shoes is not optimal. Internal factor is an error in the process of washing the shoe itself, this is caused by several factors. The first factor is the lack of supervision, this has the potential to make employees do with perfunctory. The next cause is the focus of employees disturbed due to health problems or personal problems. Next is because the employee is poorly trained in brushing shoes. The cause of the next brushing error is the error of the brushing method, in the process of Full Cleaning Service, the shoes are divided into three, namely general shoes, leather shoes, and suede shoes. The three shoes have their own brushes and slightly different washing ways, this error can be caused by two things, the first is incorrect data entry to the system, because when viewing the Service Blueprint, data input to the system are name and type of shoes, if this is wrong, it cause the wrong choice of washing method. The second error is a mistake to read the SOP order that becomes a guide for washing employees to wash shoes or the employee misread. The next cause is a brush tool that does not work optimally, this could be due to a tool that has been damaged or the tool has never been check periodically.

5. FTA for Input the wrong address

Errors in the process write the address may cause errors in shoe delivery processes that have been discussed in previous FTAs. Record errors can occur because employees are less focused in recording, even though the info provided is correct and the employee heard correctly. This is because employees have health problems or personal problems that interfere with his mind that has been discussed in the previous FTA. The second cause is the conventional method of recording. Viewing Service Blueprint in attachment 1 , the process of recording the address is done via phone, this causes 2 errors that lead to wrong in recording the address, the employee is mishearing the info and the customer is giving wrong information. The manual input can cause confusion, lost, and untidy.

There is 6 suggestion based on the root cause that has been identified with FTA and after discussed with the owner, and they agree to implement the suggestion. After 2 weeks of implementation, the error was measured in each process. The implementations are :

1. Briefing and feedback between owners and employees every day at 9.30 AM

2. Money lending policy for the urgent needs of the employee. This policy is welcomed by employees, but in the period of implementation, no employee has used this facilitation so the effect is not yet known.

3. Method of recording the customer address is changed to send location method using Google maps via WhatsApp application. This method is deemed to be effective and making the delivery process is running smoothly. The problem arises if the customer does not understand how to use send location feature and the employee need to take time to explains. In the implementation, from 50 times observation, this only happens 2 times. 
4. Cleaning and maintenance of the tools regularly. The initial plan is to clean the brush after cleaning each pair of shoes, but after implementation, the owner decides to clean the brush every 4 pairs of shoes because it deemed to be more effective.

5. Guidance for the employee about the shoe material. The sample of shoe material placed in a cardboard with the name of the material underneath. the sample. In the implementation, the employee never asked the owner to ensure the shoe material and there is no mistake in deciding the methods for cleaning shoes.

6. Motivation cards containing informative and persuasive sentences about keeping shoes clean for customers. The cards are 9x5 cm in size and put into packaged shoes. The results of this implementation not yet known.

After the implementation, the error in each process was measured and it is found a decreased error in each process. There were $64 \%$ error free process after implementation.

\section{Conclusion}

The proposed model can describe the fail point in the service process in a shoe laundry using Service Blueprint can identify the most urgent process that needs to improve first and identify the root cause using FMEA and find the root cause using FTA, so the solution can be proposed. The implementation shows that there is a decreased of error in the service process, but due to the short time in implementation, it is suggested to measure after some period of time to do a quality check. Further research should use the model in other service setting to give this model generalizability since this is the first research.

\section{References}

1. Adidas Shop. https://shop.adidas.co.id/pria/sepatu/training.html (retrieved September 2017)

2. Nike Store. https://store.nike.com/id/en_gb/pw/mens-shoes/7puZoi3?ipp=120 (retrieved September 2017)

3. C. Grönroos, Service Management and Marketing: Managing the Service Profit Logic (John Wiley \& Sons, United Kingdom, 2015)

4. V.A.Zeithaml, M.J.Bitner, D.D.Gremler, Services Marketing: Integrating Customer Focus Across the Firm (McGraw-Hill, New York, 2013)

5. C. McCain, Using an FMEA In a Service Setting. Quality Progress 39, 9 (2006)

6. W.E.Vesely, F.F.Goldberg, N.H.Roberts, D.F.Haasl, Fault Tree Handbook, US Nuclear Regulatory Commission (Washington, DC, 1981)

7. Y.Geum, H.Seol, S.Lee, Y.Park, Application of fault tree analysis to the service process: service tree analysis approach, Journal of Service Management 20, 4:433-54 (2009)

8. A.A.P.de Carvalho, C.A.Scapin, Service fault tree analysis: its use for improving the efficiency of service processes: Annual Reliability and Maintainability Symposium, Proceeding p. 186-9 (2002)

9. P.T.Chuang, Combining Service Blueprint and FMEA for Service Design, The Service Industries Journal 272 p.91-104 (2007)

10. M.J.Bitner, A.L.Ostrom, F.N.Morgan, Service Blueprinting: A Practical Technique for Service Innovation, California Management Review (2007) 